\title{
Crise e reforma do Estado: uma questão de cidadania e valorização do servidor
}

\section{A Crise do Estado: Governabilidade e Governança}

Dois componentes são fundamentais quando se trata de implementar programas de mudança na administração pública: a governabilidade e a governança. $\mathrm{O}$ primeiro diz respeito às condições de legitimidade de um determinado governo para empreender as transformações necessárias, enquanto que o segundo está relacionado a sua capacidade de implementá-las. Essa capacidade abrange tanto condições técnicas/administrativas, quanto financeiras.

Durante muito tempo, a crise do Estado na América Latina e, em particular, no Brasil se caracterizou, fundamentalmente, por uma crise de governabilidade, dado que os processos de escolha e seleção dos governantes careciam de legitimidade, por seu caráter nem sempre democrático de implementação. Nesse contexto, a questão central colocada era a da inviabilidade de proceder às reformas estruturais por falta de credibilidade e, por conseguinte, de comprometimento da sociedade com o conjunto de mudanças a implementar. Esse estágio, ainda que não completamente superado na região, apresenta sinais positivos de evolução, a partir dos avanços nos processos de democratização, que tomam ares de irreversibilidade, aumentando a confiança na hipótese de superação da crise. Na verdade, a questão da governabilidade assume outra perspectiva, dado que a legitimidade assegurada por processos

Caio Márcio Marini Ferreira é Diretor da Secretaria da Reforma do Estado do Ministério da Administração Federal e Reforma do Estado 
eleitorais democráticos nem sempre se traduz em condições efetivas de implementar reformas estruturais que, muitas vezes, dependem de complicados processos de negociação entre poderes, notadamente nos regimes presidencialistas. Entretanto, ainda que garantida a governabilidade, esta não é suficiente para produzir a mudança, o que coloca em relevo a necessidade de ampliar a governança, como ingrediente determinante da estratégia de enfrentamento da crise, a partir de duas manifestações centrais: a crise financeira e a crise de desempenho.

A primeira responde pela incapacidade do Estado contemporâneo de geração de poupança pública positiva, que lhe permita realizar os investimentos sociais e de infra- estrutura necessários, já que o custeio da máquina compromete a maior parte da arrecadação (BResser Pereira, 1996).

A segunda se caracteriza pela baixa qualidade na prestação dos serviços públicos, gerando insatisfação por parte da sociedade pelo não atendimento de seus requerimentos básicos. Ainda que esta situação não deva ser generalizada para toda a administração pública, o déficit de desempenho vem se agravando e gerando, como consequiência, deterioração da imagem do serviço público perante a sociedade.

Desta forma, o desafio de reformar o Estado está circunscrito no contexto de mudança social, política e econômica que caracteriza o momento atual. Essa enorme tarefa de transformação impõe ao Estado a necessidade de rever seus papéis, funções e mecanismos de funcionamento, mas isso não é suficiente. O momento de transformação impõe, da mesma forma, novas exigências à sociedade como um todo, incluindo aí seus diversos segmentos. O objetivo é comum e trata, fundamentalmente, de encontrar alternativas de superação das desigualdades, ampliando o espaço de inclusão na vida social, política e econômica na direção do desenvolvimento, a partir da internalização dos conceitos de cidadania e equidade. Isso, certamente, obrigará à adoção de abordagens não convencionais na construção da estratégia de enfrentamento da crise, o que passa, seguramente, pela construção e fortalecimento de mecanismos de parceria Estado-Sociedade. Isoladamente, as forças direcionadas para a mudança perdem vitalidade e objetividade. Portanto, é necessário consolidar alianças que assegurem sinergia, a partir da ampliação da consciência de cidadania e da proposição de soluções criativas e inovadoras que garantam legitimidade e viabilidade às transformações exigidas pela sociedade.

Este cenário dá um caráter emergente à necessidade de reformar o Estado e, mais particularmente, o seu aparato adminis- 
trativo, a partir de três movimentos centrais: o primeiro voltado para

a dimensão financeira da crise, enquanto que o segundo e o terceiro orientados para a superação da crise de desempenho. São eles:

- a busca permanente de aumento da eficiência da máquina pública, por intermédio da racionalização e incremento de produtividade (fazer mais com menos);

- a melhoria contínua da qualidade na prestação dos serviços públicos, visando atender aos requerimentos da sociedade no que diz respeito à satisfação das demandas sociais básicas (fazer melhor);

- o resgate da esfera pública como instrumento de expressão da cidadania e fórum de aprendizado social (fazer o que deve ser feito).

\section{O esgotamento do paradigma burocrático}

Kliksberg (1987) faz um balanço de trinta anos de reformas administrativas na América Latina, apontando elementos positivos e negativos nesses processos. Como positivos destaca: o desenvolvimento de alta sensibilidade sobre a necessidade de reforma junto à opinião pública; o estabelecimento de instituições especializadas de pesquisa e capacitação sobre o tema; e a formação de profissionais latino-americanos que representem respeitável massa crítica no campo da reforma administrativa. Não obstante, esses movimentos de reforma não concretizaram os reais objetivos de transformação pretendidos. Em seguida, Kliksberg procura analisar as razões desse insucesso, que não deve ser imputado à falta de apoio político ou econômico, como muitos insistem, mas à necessidade de revisão da base conceitual de fundamentação dos processos de mudança na administração pública. Dentre esses pontos merecem destaque: a natureza da mudança administrativa, que enfatizou reformas globais e mudança formalista da ordem jurídica e institucional tendo produzido, como conseqüência, simples redesenhos de organogramas, normas e legislação. Em contraposição, a tendência dominante recomenda o "realismo administrativo", que consiste na adoção de uma estratégia seletiva, baseada na atuação sobre pontos de estrangulamento e avanços sucessivos. Outro aspecto é o da dicotomia entre política e administração, que parte do pressuposto da existência de uma direção política, eleita pela população, e um aparato administrativo que a executa, que, se não cumpre o determinado, o faz por uma 
questão meramente técnica, exigindo, como medida corretiva, a modernização desse aparato. Na verdade, essa abordagem desconsidera a existência de três tipos de grupos que determinam os movimentos das organizações: os grupos intraburocráticos de pressão, os grupos externos à organização e os usuários dos serviços. Além desses, o autor assinala a necessidade de revisão dos modelos obsoletos de percepção da realidade, tanto na ótica dos formuladores de políticas, quanto na dos planejadores e reformadores do Estado; também destaca a pobreza do pensamento estratégico, que prioriza a introdução de metodologias de simplificação antes de uma análise global da efetiva necessidade da realização da atividade, tendo como conseqüência o risco de se fazer melhor o que não precisa ser feito. Finalmente, aponta o problema da política de pessoal meramente logística, baseada no estabelecimento de controles ao invés de privilegiar a introdução de mecanismos voltados para a motivação e participação dos funcionários.

Assim, a realização dos objetivos da reforma do aparelho do Estado passa, necessariamente, pelo questionamento da suficiência do paradigma burocrático vigente.

O modelo de administração pública burocrática surge com a preocupação de combater os excessos do modelo patrimonialista, caracterizado pela confusão entre o interesse público e o privado: o Estado, nessa visão, era quase que uma extensão da família real e tinha como atribuição fundamental administrar os bens da realeza. As conseqüências inevitáveis dessa abordagem foram: corrupção, clientelismo, fisiologismo etc. No sentido de combater essa lógica ingrata do patrimonialismo, o sociólogo alemão Max Weber analisa o modelo burocrático como forma de desenvolvimento da sociedade capitalista, a partir de suas reflexões sobre as formas de expressão da autoridade, definindo os atributos da organização racional-legal. Esses atributos estão voltados para a garantia da funcionalidade: a impessoalidade, a formalização, a divisão do trabalho, a hierarquização e a competência técnica baseada no mérito. Segundo Guerreiro Ramos (1966: 254), Weber foi quem, pela primeira vez, conferiu à burocracia o significado de elemento característico de sistemas sociais relativamente avançados, a partir da seguinte definição: "agrupamento social que rege o princípio da competência definida mediante regras, estatutos, regulamentos, da documentação, da hierarquia funcional, da especialização profissional, da permanência obrigatória do servidor na repartição durante determinado período de tempo, e da subordinação do exercício dos cargos a normas abstratas." 
Nesse sentido, a implementação dos princípios do modelo burocrático cumpriu com propriedade o papel de frear a lógica patrimonialista e foi determinante tanto na administração pública, quanto na de empresas, onde também foi importante mecanismo de profissionalização das empresas familiares.

Entretanto, ainda que o modelo não tenha sido integralmente implementado, a sua adoção passou a ser questionada. Vale mencionar que a crítica ao modelo burocrático não é nova, nem original. Todas têm em comum certa reverência e reconhecimento ao criterioso e consistente modelo, concebido por Weber. Não obstante, foi observado que tanto o excesso na aplicação das categorias traz imperfeições à administração, quanto a ausência destas mesmas categorias pode conduzir a situações anárquicas. Esta, em essência, é a crítica de Merton (1957), quando fala da disfuncionalidade da burocracia, ao examinar as suas conseqüências imprevistas. Já Amitai Etizioni (1967) considera exagerada a distinção entre as três formas de autoridade e de estrutura social: a tradicional, justificada pelo conformismo, a carismática, baseada no personalismo do líder e a burocrática (a legítima), fundamentada nas categorias da organização racional-legal antes mencionadas. Segundo ele, existem tipos mistos dependendo das circunstâncias e características do momento vivido pela organização, além do que pode-se passar de uma estrutura mais burocrática para uma mais carismática e depois voltar a ela. Por fim, Thompson (1967), ao se referir à buropatologia, insinua que um apego quase cerimonial à rotina e aos métodos habituais contribui para a resistência à mudança.

Estas referências históricas foram recuperadas com o intuito de introduzir uma nova dimensão à crítica ao modelo burocrático, dada por uma drástica transformação de contexto. Durante muito tempo, vivemos num ambiente caracterizado por poucas mudanças ou por mudanças razoavelmente estruturadas e previsíveis. Nesse contexto, dominado por certo determinismo e linearidade, a premissa que condicionou a gestão, tanto pública quanto privada, se caracterizava pela lógica em que o futuro era uma mera extensão do passado, ou o passado explicava o futuro. Nesse sentido, o problema da gestão reduzia-se a, simplesmente, olhar para trás, descobrir as leis de formação das variáveis relevantes da organização, construir um modelo explicativo para as mesmas e projetar o futuro. Vale destacar que esta ainda é a lógica determinante dos processos de orçamentação de boa parte das instituições públicas. Nesta situação, baseada numa razoável estabilidade, o modelo burocrático atendia 
às necessidades, já que seus princípios eram compatíveis com o contexto.

Entretanto, esta não é a situação atual. Vivemos hoje num ambiente caracterizado por um ritmo acelerado de transformações (a mudança é a norma) e, além disto, pela imprevisibilidade com relação às mudanças. Nesta perspectiva, o rigor no cumprimento do ritual burocrático dificulta o alcance dos objetivos institucionais. A velha lógica perde suficiência como embasamento dos processos de gestão: o sucesso no passado não garante o êxito no futuro. $\mathrm{O}$ novo recurso estratégico, diferenciador das organizações de sucesso, é a capacidade de reação veloz frente à mudança. As organizações, para sobreviver nesse contexto, precisam desenvolver a capacidade de antevisão e, além disto, necessitam de agilidade e flexibilidade para adaptar-se às novas condições e demandas externas.

\section{A experiência internacional recente}

\subsection{O modelo gerencial}

A necessidade de rediscutir o papel e as formas de funcionamento do Estado, com vistas ao atendimento dos requerimentos atuais, vem motivando o debate acerca das reformas no cenário internacional. Os desafios de implementar programas voltados para o aumento da eficiência e melhoria da qualidade dos serviços parecem ser a tendência dominante, ganhando a denominação genérica de gerencialismo na administração pública.

Conforme Aвrucio (1996), observa-se uma invasão desses conceitos no setor público dos Estados Unidos e Grã-Bretanha, a partir da eleição dos governos conservadores, tendo como ênfase inicial programas de redução de custos. Abrucio também apresenta uma classificação do modelo gerencial, a partir dos seus principais objetivos, relação com a sociedade e segundo a ordem cronológica de criação. Assim, o primeiro movimento, que foi denominado gerencialismo puro, tinha como objetivo básico a preocupação com a eficiência, economia e produtividade, pretendendo sensibilizar, desta forma, os contribuintes de impostos. Em seguida, surge o movimento do New Public Management, que incorpora a idéia da efetividade e da busca da melhoria da qualidade dos serviços, na perspectiva dos clientes/usuários destes serviços. Finalmente, o modelo evolui para a visão do Public Service Oriented, baseado na noção de eqüidade, resgate do conceito de esfera pública e 
ampliação do dever social de prestação de contas (accountabil-

ity). Essa nova visão, ainda que não completamente delimitada conceitualmente, introduz duas importantes inovações: uma no campo da descentralização, valorizando-a como meio de implementação de políticas públicas, e outra, a partir da mudança do conceito de cidadão, que evolui - de uma referência individual de mero consumidor de serviços no segundo modelo - para uma conotação mais coletiva, incluindo seus deveres e direitos.

\section{2. $O$ caso norte-americano}

A experiência recente norte-americana ganhou espaço na bibliografia técnica internacional, a partir do livro de OSBORNE \& Gaebler, Reinventando o Governo (1994). Nele, os autores exploram a idéia do governo empreendedor, inspirados na formulação original do economista francês Jean Baptiste Say: "empreendedor é aquele que transfere recursos de setores menos produtivos para setores mais produtivos". Assim, reinventar significa adequação à era da informação, desenvolvimento da capacidade criativa e inovadora para enfrentar as limitações impostas pela forte cultura burocrática dominante. Este novo modelo, denominado governo empresarial/empreendedor, se fundamenta em um conjunto de dez princípios voltados para a viabilização de um novo paradigma para a administração pública. Os principais são os seguintes:

- Governo catalisador, a partir da redefinição do papel do governo, de provedor direto para promotor (...navegar, não remar);

- Governo competitivo, que destaca as vantagens da competição (a questão não é público versus privado, mas competição versus monopólio);

- Governo da comunidade, que transfere responsabilidades da burocracia para o cidadão;

- Governo orientado por missões e resultados, que muda o enfoque em regras e procedimentos para missões e resultados;

- Governo voltado para clientes, que destaca o papel preponderante do governo de servir aos cidadãos com qualidade e enfatizando o controle social.

Osborne transformou-se em importante assessor do vicepresidente $\mathrm{Al}$ Gore na condução da reestruturação da administração pública norte-americana, que teve como objetivos a melhoria da qualidade e a racionalização dos gastos. O registro mais significativo desta experiência está num relatório apresentado por Al Gore ao Presidente Clinton, em setembro de 1993: o The National Performance Review. Neste documento são identificados 
os principais obstáculos à implementação dos princípios do

Reinventando o Governo, com destaque para o excessivo monopólio estatal, alto grau de burocratização, a falta de incentivos para o sucesso e a impunidade nos casos de fracasso, além da ausência de mecanismos que encorajem processos criativos voltados para a inovação. Toda a máquina está concentrada nos controles burocráticos: "No mundo altamente politizado de Washington, o maior risco não é que um programa tenha um baixo desempenho, mas que surja um escândalo". Finalmente, o Relatório aponta para algumas soluções, enfatizando a necessidade de estudar os casos de sucesso. Por anos, o governo tem estudado os fracassos e os fracassos têm persistido. No Relatório são propostas: a redução significativa da burocratização, liberando as organizações para cumprir as suas missões; a focalização no consumidor; a delegação de poder aos empregados; e a racionalização.

\subsection{O caso inglês}

A marca registrada da administração pública inglesa é dada pela nítida separação entre administração e política, que tem como objetivo garantir a neutralidade e proteção contra as alternâncias de poder. Esta separação garante, em tese, duas impossibilidades: de funcionários participarem da vida política e de políticos tirarem proveito dos cargos administrativos, com exceção dos cargos diplomáticos, alta direção e direção de estatais. A progressão funcional dentro da carreira decorre, fundamentalmente, do tempo de serviço e de processos sistemáticos de avaliação, realizados pelos superiores hierárquicos.

O processo de renovação da administração pública inglesa tem como marco o relatório Fulton, elaborado em 1968. Plowden (1984), destaca o ataque ao culto do funcionário generalista: “o administrador capaz de cobrir todas as áreas, cuja capacidade era mais política do que técnica, e cuja falta de interesse na gerência constituía importante fator do fraco desempenho do governo central (e, assim, conseqüentemente, do país)". A recomendação organizacional básica do relatório era a criação de um novo Departamento de Serviço Civil, retirando do Tesouro a responsabilidade de administrar o serviço civil. Esta medida simbolizava a nova importância dada ao Departamento e sinalizava um novo estilo de administração. Outras recomendações foram a de criação de uma nova Escola Superior de Administração Civil, completa e independente, e a eliminação de divisões existentes dentro do Serviço. 
Esse período, final dos anos 60 , início dos 70 , foi marcado por significativas reestruturações, baseadas nos princípios de eficiência (criação de unidades maiores, capazes de desenvolver e manter aperfeiçoadas as estruturas gerenciais), abrangência (a ordenação da miscelânea confusa e desnorteante de jurisdições divididas e superpostas, que haviam crescido no decorrer dos anos), e autonomia municipal (criando maiores e mais eficientes unidades locais, reduzindo a intervenção central).

Entretanto, é no período Thatcher que ocorre a mais profunda reforma da administração inglesa, num contexto caracterizado pelo alto custo da máquina pública e pela baixa eficiência na qualidade dos serviços prestados.

O processo de mudança foi, inicialmente, implementado sem muita preocupação com formulações estratégicas; havia muita determinação e vontade política para a ação de transformação. O primeiro movimento foi o de reduzir os quadros e extinguir o tradicional Ministério da Função Pública. A orientação geral era ter definição clara da finalidade de cada órgão e seu custo. $\mathrm{O}$ segundo movimento foi o da privatização, algo ainda pouco experimentado internacionalmente, naquele momento. $\mathrm{O}$ terceiro, foi o da busca da melhoria da qualidade no serviço público e aumento da eficiência (fazer mais com menos). Foi criada uma pequena unidade central de coordenação (Efficiency Unit), com os objetivos de desenvolver a consciência de custos (value for money) e incentivar a competitividade. A metodologia empregada foi a da avaliação (scrutiny), que consistia no exame rigoroso de funções, processos e atividades, a partir da identificação de problemas, e na implementação de um plano de ação de curto prazo, em áreas-piloto pré-selecionadas. No período de 1979 a 1992, foram realizadas mais de 300 avaliações, gerando uma redução de custos de, aproximadamente, dois bilhões de libras. $\mathrm{O}$ quarto movimento foi o do Next Step Program, que deu origem ao processo de criação das Agências Executivas. A idéia central consistia em separar as funções de formulação das de execução das políticas públicas. Os Ministérios são responsáveis pela formulação das políticas, ficando a implementação a cargo das Agências, que, a partir dos compromissos de resultados assumidos, passam a gozar de flexibilidade administrativa, principalmente nas áreas de gestão de pessoal e gestão financeira. O Next Step Program estabelece as regras do jogo e orienta o processo. A relação do Ministério com a Agência está baseada na figura de um contrato, denominado Framework Document, que tem a seguinte estrutura: 
Apresentação, normalmente assinada pelo Ministro, contendo uma visão global da instituição.

Introdução, contendo dados básicos de identificação da Agência, como ano de criação, finalidade e recursos globais.

Planejamento Estratégico, com a definição de missão, visão, valores, metas e indicadores de desempenho.

Responsabilização (accountability), contendo as definições de responsabilidade e graus de prestação de contas de cada nível envolvido no processo (Ministro, Secretário Permanente, Diretor Geral, Membros do Parlamento etc).

Planejamento, finanças e serviços de suporte, com a descrição e detalhamento do plano, atribuições e delegações para o cumprimento dos resultados.

Pessoal, contendo definições relativas à gerência e pagamentos.

Revisão, com as regras de ajustes e variações do contrato.

Delegação financeira, contendo limites de delegação por rubrica (grandes números) para o Diretor Geral.

Finalmente, merece destaque a implementação do programa de melhoria dos padrões de prestação dos serviços públicos, denominado Citizen's Charter, baseado no incentivo à competitividade, com remuneração atrelada ao desempenho. O programa pressupõe a elaboração de um estatuto, onde se estabelecem padrões básicos de desempenho na prestação de serviços públicos (por exemplo, nos centros de saúde, os horários são marcados com antecedência e padrões de atendimento são estabelecidos). Além disso, os resultados alcançados têm ampla divulgação e são realizadas auditorias para avaliar a "performance" na prestação dos serviços.

\section{4. $O$ caso francês}

O princípio fundamental que orienta o serviço público francês é o de assegurar o interesse geral, garantindo aos cidadãos condições de igualdade, adotando, para essa finalidade, um modelo que enfatiza o caráter estatizante e centralizador.

CROzIER (1989) comenta o salto fantástico dado pela sociedade francesa, a partir de 1945, assinalando o papel de contrapeso exercido pelo Estado visando a "assegurar a estabilidade de um veleiro que anda muito rápido. Hoje, com a modernidade que a sociedade obteve (triplicação do nível de vida, duplicação da produção industrial) esta armadura se rompe por todo lado, e é o Estado que cada vez mais bloqueia o desenvolvimento". Em seguida, Crozier (1989: 55-61) analisa o significado do "Estado à francesa", destacando o papel das relações humanas como expressão das 
práticas administrativas como determinante desta filosofia estatizante: " ele está por toda parte, intervém em tudo, invade a sociedade em todos os seus aspectos". Como consequiência desse enfoque de "manter o interesse geral a qualquer preço", o Estado à francesa fortalece a lógica burocrática, privilegiando os controles, mais particularmente os controles de conformidade: "isso não é muito grave em um mundo que se transforma lentamente, mas se torna insuportável em um mundo que se transforma rapidamente, onde a inovação desempenha um papel cada vez mais decisivo". Num tom mais otimista, Crozier conclui essa reflexão apontando um cenário favorável à mudança, a partir das seguintes tendências: a) a evolução da cultura francesa conduz a maiores exigências de simplicidade nas relações sociais, encontros mais diretos, livres das barreiras do formalismo; b) renasce o espírito empreendedor, baseado na idéia de autonomia e menor dependência de ajudas ou autorizações externas para a realização das atividades: c) a força do movimento da qualidade e sua real possibilidade de utilização na função pública francesa; e d) a irreversibilidade dos processos de abertura para o exterior e aumento de competitividade.

Nesse contexto de transição em direção a um modelo menos estatizante e centralizador, a experiência francesa recente apresenta uma evolução bastante peculiar, que merece ser apreciada. $\mathrm{O}$ documento base da reforma do Estado do atual governo (Nota técnica - MARE/cooperação francesa 1996), definiu os seguintes objetivos prioritários:

- Definir o papel do Estado, focalizando os aspectos de possibilidades de parceria com o setor privado, adaptação à modernidade e à concorrência, descentralização de competências para as administrações territoriais e integração com a União Européia;

- Focalizar o cidadão, enfatizando os novos princípios de simplicidade, qualidade, acessibilidade, rapidez, transparência, mediação, participação e responsabilidade, a serem acrescentados aos princípios clássicos da neutralidade, igualdade e continuidade;

- Reformar o Estado central, a quem devem caber as funções de regulação entendidas como: previsão, análise, formulação de políticas, legislação e avaliação;

- Delegar responsabilidades, racionalizar o aparelho do Estado, renovando as relações entre o Estado central e os executores;

- Renovar a gestão dos recursos humanos, reduzindo o número de carreiras, aperfeiçoando a avaliação individual e os 
critérios de remuneração, dotando o funcionário de polivalência e capacidade de adaptação profissional;

- Renovar a gestão orçamentária, por intermédio da fixação de prioridades, melhoria dos sistemas de informação, discussão dos orçamentos futuros com base nos resultados de exercícios findos, criação de quadro orçamentário plurianual, controle e gestão orçamentários.

O processo de modernização tem enfatizado a transferência de atividades para os níveis locais, mediante desconcentração, que significa repassar a prestação de serviços para as projeções regionais da administração central, e da descentralização, que transfere funções do poder central para os departamentos ou governos locais. A descentralização, além de territorial, pode ser também funcional, por meio da transferência de atividades aos estabelecimentos públicos (algo similar às nossas autarquias), ou mesmo pela concessão ao setor privado. Estes movimentos visam a reduzir o nível central, delegando a prestação dos serviços aos níveis locais e fortalecendo o papel regulador. Outra tendência é a da contratualização das atividades dos órgãos públicos (projetos de serviço/centro de responsabilidade), apoiadas por um sistema de informações e de avaliação. A desconcentração e a descentralização visam aproximar do usuário a execução ou centro de decisão, enquanto que os projetos de serviço/centro de responsabilidade visam dotar a administração pública de maior eficiência e eficácia nos serviços e melhor atendimento ao usuário. Os centros de responsabilidade são órgãos vinculados a ministérios, geralmente "direções", que têm por competência a execução de determinados serviços - diretamente ao público ou a outros órgãos da administração, caracterizando-se pela associação do pessoal envolvido na busca da eficiência e eficácia, pela gestão rigorosa e pela determinação de resultados mensuráveis e qualificáveis, dentro de um padrão de desempenho, segundo as especificações dos projetos de serviço. Para tanto, os órgãos passam a gozar de algumas flexibilidades regulamentares e o desempenho pode ser premiado com bonificações aos funcionários. Os resultados têm sido positivos e há um interesse crescente em aumentar a experiência. A adoção dos centros de responsabilidade em um dado ministério é formalizada por uma convenção firmada entre os ministros da Economia e Orçamento, da Função Pública e do ministério interessado. A constituição de um centro se dá quando se atribui tal condição a um órgão subordinado ao ministério em questão, mediante a assinatura de um contrato, normalmente de três anos, estabelecendo compromissos e flexibilidades. 


\section{A experiência brasileira}

\subsection{Antecedentes}

A primeira experiência concreta de reforma administrativa no Brasil ocorre na década de 30, no governo de Getúlio Vargas. A preocupação central era a da introdução do modelo burocrático, de corte weberiano, na administração pública brasileira para enfrentar a expansão patrimonialista vigente. L. MARTIns (1995) analisa esse período, comentando as três diretrizes propostas por Maurício Nabuco, importante diplomata brasileiro, encarregado de estudar o assunto, junto com Luis Simões Lopes: definição de critérios profissionais para ingresso no serviço público, desenvolvimento de carreiras e estabelecimento de regras de promoção baseadas no mérito. Dentro deste espírito é criado o DASP - Departamento de Administração do Serviço Público, que assume as funções de implementar essas diretrizes, de supervisionar a administração pública e de formar os administradores públicos do primeiro escalão, além de fixar o orçamento nacional. O resultado objetivo, ainda segundo Martins, foi o estabelecimento de um duplo padrão: os altos administradores seguiram essas normas e tornaram-se a melhor burocracia estatal da América Latina; os escalões inferiores (incluindo os órgãos da área social) foram deixados ao critério clientelista de recrutamento e à manipulação populista dos recursos públicos. Com o tempo, o DASP cristaliza sua atuação, tomando ares de super-institução, afirmando os princípios de centralização e hierarquia.

Embora continue cumprindo o seu papel de profissionalização do serviço público, o Departamento começa a apresentar os primeiros sinais de disfuncionalidade. Surge a famosa expressão: é necessário fugir das "raias" do DASP. Bresser Pereira (1996) observa que, "já em 1938, temos um primeiro sinal da administração pública gerencial, com a criação da primeira autarquia, a partir da idéia de descentralização na prestação de serviços públicos para a administração indireta, que estaria liberada de obedecer a certos requisitos burocráticos da administração direta". Entretanto, continua Bresser, a primeira tentativa real de reforma gerencial na administração pública brasileira irá ocorrer em 1967, com o DecretoLei 200, sob o comando de Amaral Peixoto e inspiração de Hélio Beltrão, com o nítido objetivo de enfrentar as limitações do modelo burocrático. O referido instrumento legal, que continha aspirações descentralizadoras bastante significativas, preconizava o 
fortalecimento da administração indireta por intermédio da descentralização e da autonomia das autarquias, fundações e empresas estatais, como forma de agilizar a atuação do Estado. Entretanto, cometeu o equívoco de não repensar os mecanismos de controle, enfraquecendo, desta forma, o núcleo central do aparelho estatal responsável pela formulação das políticas públicas. Isto permitiu tanto a realização de experiências exitosas no campo da gestão pública, quanto usos indevidos das flexibilidades e autonomias, desvirtuando o objetivo proposto. Tanto assim que, em 1988, quando da promulgação da nova Constituição brasileira, que, sem dúvida, representou um avanço significativo no campo da participação popular e incorporação do valor da cidadania, houve um importante retrocesso no capítulo da administração pública, de tal sorte que, hoje, não há rigorosamente diferença significativa entre as administrações direta e indireta do ponto de vista dos graus de liberdade. Além disto, o que é mais grave, perdeu-se a cultura de gerenciamento por resultados, talvez pela ausência destas flexibilidades a partir do argumento da inviabilidade de realizar os objetivos por falta de autonomia para gerir os meios e recursos necessários. A lógica prevalecente, infelizmente, é baseada numa certa impunidade, já que fazer tudo, ou seja cumprir com os objetivos, dá no mesmo que fazer nada.

\subsection{A reforma de 1995}

\subsubsection{Preâmbulo}

A partir de 1995, o governo Fernando Henrique Cardoso estabelece uma nova estratégia para a reforma da administração pública brasileira integrada a um processo mais abrangente de reforma do Estado. A sinalização evidente desta prioridade é dada quando da transformação da então SAF — Secretaria da Administração Federal num novo ministério, que, além das funções tradicionais de gestão da função pública, assume o papel de coordenador do processo de reforma do aparelho do Estado. Este novo ministério, denominado MARE - Ministério da Administração Federal e Reforma do Estado passa a funcionar desde o primeiro momento de instalação deste governo, a partir de janeiro de 1995. Também é instalada a Câmara da Reforma do Estado, instância interministerial deliberativa sobre planos e projetos de implementação da reforma, além de um Conselho da Reforma do Estado, integrado 
por representantes da sociedade civil, com atribuições de assessorar

a Câmara nesta matéria.

O primeiro semestre de 1995 foi dedicado ao desenho da estratégia, a partir da elaboração da versão preliminar do Plano Diretor da Reforma do Aparelho do Estado, que foi submetido à apreciação da Câmara quando da reunião de sua instauração, em junho, em sessão coordenada pelo Presidente da República. Em seguida, iniciou-se um processo de discussão do referido documento visando ao seu aperfeiçoamento, sendo o mesmo aprovado pela Câmara em meados de outubro.

\subsubsection{O plano diretor e a administração pública gerencial}

O Plano Diretor da Reforma do Aparelho do Estado (1995), representa, na verdade, um esforço de sistematização da estratégia de enfrentamento dos principais problemas da administração pública brasileira, num contexto que é determinado, por um lado, pela presença de uma forte cultura burocrática e, por outro, pela existência de práticas ainda patrimonialistas. Essa estratégia visa, ao mesmo tempo, criar condições para a superação desses problemas, assegurando ganhos de eficiência no aparelho do Estado e aumentos na qualidade dos serviços prestados à sociedade. Em síntese, o que se pretende é implantar o modelo de administração pública gerencial, baseado na adoção dos seguintes princípios:

- Focalização da ação do Estado no cidadão, o que significa o resgate da esfera pública como instrumento do exercício da cidadania. O Estado deve ser entendido como o fórum onde o cidadão exerce a cidadania, portanto todo e qualquer esforço de reforma deve ter como objetivos melhorar a qualidade da prestação do serviço público na perspectiva de quem o usa e possibilitar o aprendizado social de cidadania;

- Reorientação dos mecanismos de controle para resultados, o que significa evoluir de uma lógica baseada tão somente no controle da legalidade e do cumprimento do rito burocrático para uma nova abordagem centrada no alcance de objetivos. Os mecanismos de controle, na perspectiva burocrática atual representam um entrave à ação eficiente e inovadora, ao invés de ajudar representam um obstáculo à ação. Na medida do possível deverá acontecer uma evolução natural dos controles a priori para controles a posteriori baseados em indicadores de resultados;

- Flexibilidade administrativa, que permita a instituições e pessoas alcançarem seus objetivos. Não se trata de outorgar 
autonomia pela autonomia, mas sim a necessária para o alcance dos resultados. Isto exigirá a delimitação dos espaços de atuação da máquina pública, a partir do fortalecimento dos papéis de formulação de políticas e regulação, gerando, como conseqüência, um tratamento sob medida da questão, já que o grau de flexibilidade depende da natureza da atividade a ser exercida. Hoje, notadamente na administração indireta, ocorre uma realidade no mínimo curiosa, a da autonomia invertida: as instituições são bastante autônomas para decidirem sobre os seus fins, mas quase nada no que diz respeito aos meios;

- Controle social, o que quer dizer desenhar mecanismos de prestação social de contas e avaliação de desempenho próximos da ação. Se o objetivo é o resgate da cidadania e a reorientação para resultados, este controle não pode se limitar apenas à dimensão interna, com base em quem presta o serviço. Tem que ser na perspectiva de quem usa ou se beneficia da prestação dos serviços públicos;

- Valorização do servidor, que representa, na verdade, a âncora do processo de construção coletiva do novo paradigma, orientado para o cidadão e realizado pelo conjunto dos servidores de forma participativa. Implantar o modelo de administração pública gerencial não significa mudar sistemas, organizações e legislação; muito mais do que isso, significa criar as condições objetivas de desenvolvimento das pessoas que conduzirão e realizarão as reformas. Nesse sentido, valorizar o servidor quer dizer estimular sua capacidade empreendedora, sua criatividade, destacando o espírito público de sua missão e o seu comportamento ético visando o resgate da auto-estima e o estabelecimento de relações profissionais de trabalho.

Não se trata simplesmente da aplicação direta de princípios da administração de empresas na gestão pública; nem tampouco de abandonar as categorias da burocracia clássica por completo. $\mathrm{O}$ importante é fazer as apropriações e adaptações necessárias no sentido de dotar a administração pública de um modelo que, efetivamente, a ajude cumprir com suas finalidades. Em complemento, o plano diretor aprofunda, na conceituação do modelo proposto:

"A administração pública gerencial inspira-se na administração de empresas, mas não pode ser confundida com esta última. Enquanto a receita das empresas depende dos pagamentos que os clientes fazem livremente na compra de seus produtos e serviços, a receita do Estado deriva de impostos, ou seja, de contribuições obrigatórias, sem contrapartida direta. Enquanto o mercado controla a 
administração das empresas, a sociedade - por meios políticos eleitos — controla a administração pública. Enquanto a administração de empresas está voltada para o lucro privado, para a maximização dos interesses dos acionistas, esperando-se que, através do mercado, o interesse coletivo seja atendido, a administração pública gerencial está explícita e diretamente voltada para o interesse público.

Neste último ponto, como em muitos outros (profissionalismo, impessoalidade), a administração pública gerencial não se diferencia da administração pública burocrática. Na burocracia pública clássica existe uma noção muito clara e forte do interesse público. A diferença, porém, está no entendimento do significado do interesse público, que não pode ser confundido com o interesse do próprio Estado. Para a administração pública burocrática, o interesse público é freqüentemente identificado com a afirmação do poder do Estado. Ao atuarem sob este princípio, os administradores públicos terminam por direcionar uma parte substancial das atividades e dos recursos do Estado para o atendimento das necessidades da própria burocracia, identificada com o poder do Estado. O conteúdo das políticas públicas é relegado a um segundo plano. A administração pública gerencial nega essa visão do interesse público, relacionando o interesse público com o interesse da coletividade e não com o do aparato do Estado" (Plano Diretor da Reforma do Aparelho do Estado, 1995).

\subsubsection{O redesenho institucional proposto}

Para implementar a administração pública gerencial foi necessária a proposição de um modelo conceitual que melhor explicasse o funcionamento do aparelho do Estado. Obviamente, a opção de construção de um modelo traz implicitamente o inconveniente da imperfeição: um modelo é sempre uma simplificação da realidade, mas a alternativa à não utilização do modelo induziria a optar-se por uma estratégia com um grau de generalidade tal que, certamente, não geraria contestações mas, também não atacaria os problemas com a especificidade requerida. Assim, a proposta de reforma do aparelho do Estado supõe os seguintes quatro setores:

- Núcleo estratégico, entendido como o setor do Estado que edita leis, formula políticas e busca assegurar o seu cumprimento. É representado pelo Legislativo, Judiciário e, no Executivo, pela cúpula que decide sobre a formulação de políticas; 
- Atividades exclusivas, que são aquelas atividades indelegáveis e para o seu exercício é necessário o uso do poder de Estado, como por exemplo, a polícia, as forças armadas, a fiscalização, a regulamentação, o fomento;

- Serviços não-exclusivos, que são aqueles relativos normalmente à prestação de serviços de alta relevância ou os que envolvem economias externas e não podem ser adequadamente recompensados no mercado através da cobrança dos serviços. Além disto, a prestação desses serviços não implica a utilização do poder de Estado, e são, por exemplo as universidades, os hospitais, os centros de pesquisas, os museus;

- Produção de bens e serviços para o mercado, representado pelo setor de infra-estrutura, onde atuam as estatais, e que apresenta tendência de privatização.

Esta classificação permite a reflexão sobre três aspectos fundamentais relacionados à necessidade de reforma do aparelho do Estado.

A primeira diz respeito à forma de administração mais adequada para cada um dos setores antes mencionados. Para o núcleo estratégico, por suas características mais estáveis ligadas às condições adequadas para a formulação de políticas, o modelo buracrático com avanços na direção do modelo gerencial parece ser a forma mais recomendada. A idéia de carreiras, concursos públicos mais rígidos e estabilidade do servidor parece adequada à realidade e dinâmica do setor. Já para os demais, recomenda-se a utilização do modelo de administração pública gerencial.

A segunda reflexão está relacionada à forma de propriedade mais adequada para a realização eficaz dos objetivos de cada setor. Esta, certamente, é uma discussão polêmica, interessante e pouco aprofundada na realidade brasileira. Normalmente, quando se discute sobre formas de propriedade, a discussão se limita aos dois extremos da questão: privada ou estatal. Quanto ao núcleo estratégico e o setor de atividades exclusivas, a propriedade deve ser estatal, enquanto que, para o setor de produção para o mercado, a tendência natural é a da propriedade privada. Já no setor de serviços nãoexclusivos a história é diferente. Há um terceiro setor pouco considerado quando desta discussão: a esfera pública não-estatal, que se apresenta como uma alternativa bastante viável para este setor. Ela é composta de organizações voltadas para a prestação do serviço público, portanto organizações sem fins lucrativos, mas que não pertencem ao aparelho do Estado. Bresser Perreira (1996: 27-28) explora este conceito a partir da divisão clássica do Direito entre Direito Público e Privado, onde o Direito Público foi identificado com o Direto Estatal e o Privado foi entendido como 
englobando as instituições não-estatais sem fins lucrativos, que, na

verdade, são públicas. Observa que:

"O reconhecimento de um espaço público não-estatal tornou-se particularmente importante em um momento em que se aprofundou a dicotomia Estado-setor privado, levando muitos a imaginar que a única alternativa à propriedade estatal é a privada. A privatização é uma alternativa adequada quando a instituição pode gerar todas as receitas da venda de seus produtos e serviços, e o mercado tem condições de assumir a coordenação de suas atividades. Quando isto não acontece, está aberto o espaço para o público não-estatal. Por outro lado, no momento em que a crise do Estado exige o reexame das relações Estado-Sociedade, o espaço público não-estatal pode ter um papel de intermediação ou poder facilitar o aparecimento de formas de controle social direto e de parceria, que abrem novas perspectivas para a democracia".

Finalmente, a terceira reflexão está orientada para o escopo institucional mais adequado, tendo em vista o modelo conceitual proposto. Assim, para o núcleo estratégico mantém-se a estrutura similar ao que hoje se denomina administração direta. Para o setor de atividades exclusivas, o modelo institucional proposto é o de agências executivas, que representam um esforço de recuperação do conceito original de autarquia e fundação, perdido com a Constituição de 1988, naturalmente ajustado à nova realidade do controle por resultado. Para o setor de serviços não-exclusivos o modelo é o das organizações sociais, que são entidades públicas não-estatais que têm autorização do parlamento para participar do orçamento público. Finalmente, para o setor de produção para o mercado a alternativa institucional mais adequada é a de empresa, pública, estatal ou privada. Vale ressaltar, que em todos os casos, Agências, Organizações Sociais ou Empresas, a relação com o núcleo estratégico será formalizada por meio de contratos de gestão a partir do estabelecimento de compromissos de resultados e a contrapartida de recursos e autonomias necessários.

\subsubsection{A estratégia}

A reforma do Estado, mais do que um conjunto de intenções, é um processo complexo e permanente, que requer, para o seu pleno desenvolvimento, objetividade, persistência e construção de uma estratégia que permita enfrentar conflitos e ambigüidades. Num contexto determinado por profundas transformações, nem sempre 
previsíveis, torna-se fundamental criar as condições que garantam a irreversibilidade dos processos de mudança.

Assim, realizar a reforma do aparelho do Estado, implica, na verdade, em realizar três grandes reformas, ou, em outras palavras, realizar a reforma a partir de três dimensões estratégicas básicas:

A dimensão institucional-legal, que tem por objetivo o aperfeiçoamento de todo o sistema jurídico-legal vigente que represente obstáculos à implementação do modelo de administração pública gerencial. Isto implica a necessidade de operacionalizar alterações de ordem constitucional na legislação corrente, nas normas e procedimentos em geral.

A segunda diz respeito à dimensão cultural, que visa substituir a cultura burocrática dominante pela gerencial. O Plano Diretor assinala: " os indivíduos são vistos como essencialmente egoístas e aéticos, de forma que só o controle a priori, passo a passo, dos processos administrativos permitirá a proteção da coisa pública. A mudança para uma cultura gerencial é uma mudança de qualidade. Não se parte para o oposto, para uma confiança ingênua na humanidade. O que se pretende é apenas dar um voto de confiança provisório aos administradores, e controlar a posteriori os resultados".

A terceira dimensão, muito próxima da segunda, é a da gestão, onde efetivamente se processa e se implementa a reforma. Consiste basicamente da introdução de novos princípios e técnicas de administração voltados para a melhoria do desempenho das instituições públicas. Isto pressupõe dois movimentos centrais de modernização: o primeiro, numa perspectiva global, a partir da implementação de um programa de qualidade e participação, que inclui a reestruturação estratégica, estabelecimento de compromissos de resultados e desenvolvimento de recursos humanos; e o segundo, numa perspectiva mais localizada, a partir da seleção de unidades-piloto de experimentação, que tem por objetivo transformar as atuais organizações dos setores de atividades exclusivas e não-exclusivas de Estado respectivamente em Agências Executivas e Organizações Sociais, incluindo a reestruturação e capacitação necessárias para a assinatura de contratos de gestão.

Estas dimensões, embora guardem certa independência, no limite se complementam. Naturalmente é possível avançar na direção das mudanças cultural e de gestão, ainda que mantido o status atual da legislação vigente. Mas até certo ponto: a verdadeira reforma implica a realização integral das três dimensões enunciadas, ou seja, não se realiza a reforma do aparelho do Estado a partir de uma só perspectiva do problema. Em outras palavras, e tendo outra vez CROzIER (1989: 62-63) como referência, não se faz reforma por decreto: "as medidas legislativas e executivas têm 
sua importância, às vezes decisiva, mas não é dessa maneira que se transforma um conjunto institucional. A diferença estará nos homens e na organização feita por eles. Convém, portanto, influir sobre os homens e sobre o conjunto institucional que eles constituem".

\section{O futuro da gestão pública: impactos do modelo da administração pública gerencial}

\subsection{Mudando através das pessoas}

Antes de discutir os impactos do modelo da administração pública gerencial nos sistemas básicos de gestão, é necessário discutir, ainda que simplificadamente, as tendências de transformação dos papéis e formas de atuação do Estado a partir das experiências nacional e internacional recentes.

Uma primeira tendência parece ser a de concentração das ações do Estado naquelas funções típicas, visando suprir com qualidade as demandas sociais básicas. Outra, diz respeito a sua maneira tradicional de atuação, onde parece irreversível a tendência de evolução de um papel meramente executor do atendimento das demandas sociais para o de promotor. Parece existir uma certa confusão quando se trata do verdadeiro papel do Estado no campo da prestação dos serviços sociais. Uma coisa é imaginar que seu papel é o de atender a estas demandas, outra é entender que seu papel é o de garantir que estas demandas sejam atendidas. $\mathrm{O}$ exame da experiência recente parece indicar que as reformas empreendidas, tanto no contexto nacional, quanto no internacional, não são reformas voltadas simplesmente para a melhoria da capacidade de execução do Estado; elas têm como objetivo central ampliar as capacidades de garantia da prestação dos serviços. Em tese, para o cidadão deveria ser transparente esta questão, que é de arranjo interno do aparato estatal. Fazer diretamente, no âmbito central ou local, ou fazer indiretamente através de parcerias com organizações não-governamentais, ou ainda através do setor privado não é a questão central. O importante é fazer, e fazer garantindo qualidade, quantidade e eqüidade na prestação destes serviços. Esta discussão indica uma expansão do espaço público não-estatal e fortalecimento do aparelho do Estado como formulador e regulador das políticas públicas. Na prática, entretanto, a indefinição institucional, típica desse momento de transição, leva o Estado a 
assumir papéis e funções nem sempre compatíveis com as características desejáveis, da mesma forma que induz a superposição de atuação ou, ainda, omissão em áreas estratégicas. O ideal seria concluir a discussão sobre os papéis e funções do Estado que a sociedade deseja para, em seguida, iniciar o movimento de mudança, promovendo os ajustes necessários. Entretanto, nem sempre é possível seguir esse caminho, porque a discussão sobre papéis é uma discussão sem fim e porque a emergência da crise exige ação. Assim, a realidade impõe uma estratégia onde, simultaneamente, se pensa sobre o futuro e se age sobre o dia-adia. Como conseqüência, surgem ambigüidades e conflitos que precisam ser administrados.

Nesse sentido, torna-se necessário traduzir os impactos dessa nova abordagem aos sistemas de apoio à gestão pública, como o planejamento governamental, o orçamento, a gestão financeira, a modernização administrativa e a gestão de pessoal. Hoje, predomina uma lógica bastante centralizadora e rígida nesse campo, como resposta à crise fiscal do Estado e à incapacidade real de estabelecimento de prioridades, dada a ausência de políticas públicas consistentes. Como estão cada vez mais escassos os recursos, administra-se 'na boca do caixa' a partir do contingenciamento e de cortes lineares, atendendo somente o emergencial. Essa prática, ainda que compreendida situacionalmente, não se sustenta, porque retira do administrador a responsabilidade do resultado final. Como não há minimamente autonomia sobre os meios (não se pode contratar, promover, demitir, comprar, gerir as finanças), não se responsabiliza pelos resultados. Reverter essa situação significa reconstruir a capacidade analítica do Estado a partir da delimitação clara e objetiva de seus novos papéis e do redesenho de sistemas de apoio compatíveis com esse cenário. É preciso:

- resgatar, em outras bases, a cultura de planejamento perdida;

- evoluir de um orçamento, hoje considerado como peça de ficção, para: a) um instrumento gerencial, vinculado ao planejamento e flexível, e b) um instrumento de viabilização do controle social (o orçamento participativo);

- conceber uma nova sistemática de gestão financeira que assegure a disponibilidade de recursos de forma coerente com os compromissos de resultados;

- construir uma consciência de custos na administração pública que permita avançar na busca da eficiência; 
- modernizar as estruturas organizacionais, que devem ser leves, flexíveis, descentralizadas, horizontais, reduzindo níveis hierárquicos;

- repensar o controle;

- e, fundamentalmente, construir uma política de recursos humanos que assegure e delimite o espaço do novo servidor do público.

Implementar processos de transformação organizacional tem, no desenvolvimento das pessoas seu fator chave de sucesso, representa a âncora deste processo: eu não mudo as organizações, mudo as pessoas, que promovem processos de mudança organizacional. Neste sentido, dois aspectos são fundamentais. $\mathrm{O}$ primeiro, já discutido anteriormente, trata da organização orientada por missões. Se não houver uma clara e objetiva declaração de missão, e um alto grau de compartilhamento junto às pessoas, não haverá condições favoráveis para implementar a mudança. Outro aspecto relevante é o da delegação de poderes e competência para implementá-las (empowerment). É necessário aumentar o poder de decisão das equipes e indivíduos no sentido de viabilizar a ação, naturalmente tendo como contrapartida a responsabilização por resultados. Como conseqüência, será necessário realizar um amplo programa de sensibilização, buscando assegurar o comprometimento das pessoas, além da capacitação dos quadros para a nova realidade da administração pública.

Essa nova realidade exigirá uma nova gerência. Mais do que gerência, liderança, pois o novo contexto caracterizado por profundas transformações, vai demandar habilidades de negociação e administração de conflitos. SENGE (1990), discutindo a nova visão de liderança nas organizações, destaca três funções básicas do dirigente: a) o dirigente como projetista, enfatizando que para o exercício de seu papel de liderança é fundamental sua atuação desde a etapa de projeto da organização; b) o dirigente como guia, rompendo com a visão tradicional que separa, nas organizações, os pensadores dos executores, transformando o dirigente no orientador dos diversos objetivos da sua equipe; c) o dirigente como professor, responsável pela promoção das condições de aprendizagem, ajudando as pessoas no desenvolvimento de suas habilidades.

Finalmente, no campo da avaliação do desempenho dos recursos humanos, será fundamental proceder a modificações significativas. Não faz mais sentido aquela avaliação tradicional focada no desempenho individual. Esta postura induz à competição selvagem que em nada ajuda o desenvolvimento das organizações. Neste campo a tendência tem sido a de vincular o desempenho 
mais às equipes que ao indivíduo, num espírito muito mais de cooperação que de competição.

\subsection{Uma nova visão do planejamento}

Num ambiente caracterizado por profundas transformações e pela imprevisibilidade das mudanças, o planejamento assume papel determinante. Mas certamente não se trata do planejamento que estamos acostumados a fazer. Muda o conceito e muda o método. Aquela velha lógica determinista e linear, coerente com um contexto de estabilidade, quase imutável, dá lugar a um processo mais dinâmico e ágil baseado na adoção de uma postura estratégica ao invés do simples cumprimento de ritos metodológicos. Antes era possível imaginar processos, quase rituais, em que as organizações, diante de um problema, idealizavam a solução em dois momentos: um do planejamento e outro da operação. Para isto, isolavam-se da sua realidade, desligavam o mundo real por algum tempo e produziam um belo documento com missões, análises de ambiente, objetivos, metas, indicadores, programações, orçamentos e, depois de alguns meses, religavam o mundo para implementar o plano salvador. Certamente este plano enfrentaria uma realidade completamente distinta da imaginada na etapa de formulação. Hoje, mais do que preciosismos metodológicos, a organização moderna necessita de prontidão. Perde o sentido a eterna discussão se o processo deve orientar-se de cima para baixo ou de baixo para cima, o relevante está em conseguir fazê-lo de fora para dentro. O método, se preciso, é o "planefazendo", e para isto é fundamental desenvolver duas capacidades: a de antevisão e de adaptação, simultaneamente! Neste contexto, as organizações orientadas por visões fazem a diferença. Ter uma bela e inspiradora visão e compartilhá-la dentro da organização, não significa adivinhar o futuro, significa sim, construí-lo. Uma visão tem força, mais do que isto tem poder, pode substituir o líder nos seus impedimentos, funcionando como orientadora das ações institucionais.

Sobre os enfoques alternativos ao planejamento convencional, voltados para a realidade do setor público, convém examinar a importante contribuição do economista chileno Carlos Matus contida no livro Política, Planejamento e Governo e o artigo do indiano Ravi Ramamurti, Planejamento Estratégico em Empresas Dependentes de Governo. 


\subsection{Repensando o controle}

A implementação do modelo de administração pública gerencial induz a duas importantes reorientações nos sistemas tradicionais de controle: uma de foco, outra de forma. Algumas iniciativas já apontam nesta direção, mas outras precisam ser rapidamente realizadas.

A primeira das reorientações trata especificamente da necessidade de fazer evoluir o controle voltado ao cumprimento do rito burocrático, na direção do controle por resultados. Hoje, sem risco de cometer exageros, pode-se afirmar que o controle, quando existe, está preocupado, tão somente, com a legalidade da ação administrativa: o bom administrador é o que cumpre o rito, o manual, o que segue a cartilha, e não o que atinge os objetivos. Recentemente a imprensa noticiou que um prefeito recebeu recursos para construir duas escolas e fez três e por isto está sendo questionado. Se tivesse feito uma, mas seguido rigorosamente o rito, nada aconteceria. Claro que não se está propondo o descumprimento dos dispositivos legais vigentes, mas, certamente, algo precisa ser feito, incluindo aí revisões na legislação, no sentido de garantir um controle mais efetivo dos resultados. Além disto, é necessário recuperar a cultura perdida de planejamento, desenvolver novos métodos e introduzir novos valores voltados para o controle de resultados. Neste sentido, a utilização de instrumentos, como o contrato de gestão, por exemplo, pode ajudar a realizar este importante desafio. Vale destacar que a questão não se limita a simplesmente introduzir este instrumento, mais do que isto o objetivo é o de implementar uma nova filosofia de controle baseada na avaliação dos resultados.

A segunda reorientação está voltada para os meios de realização do controle, se interno ou externo. Quando se aborda esta questão, duas dimensões do problema vêm à tona: o controle da eficiência e o da efetividade. O primeiro está centrado na análise da relação insumo/produto: quão eficiente é a organização na alocação dos insumos para a obtenção dos produtos? Outra questão é saber qual o verdadeiro impacto dos produtos junto aos usuários dos serviços prestados pela organização? O que mudou, na realidade com os produtos gerados? Esta segunda dimensão coloca a necessidade de encontrar caminhos que viabilizem o controle social, aproximando, cada vez mais, a prestação dos serviços aos níveis locais de governo e explorando o espaço público não-estatal, o que permite uma realização mais direta do controle por parte dos cidadãos-usuários dos serviços prestados. 
Algumas experiências apontam a tendência nessa direção. No Brasil, a experiência do SUS - Sistema Único de Saúde, baseado na integração de esforços das esferas de governo na prestação de serviços na área de saúde pública, sob a supervisão de conselhos comunitários; a proposta de fortalecimento do espaço público não- estatal por intermédio da implantação das organizações sociais cujo conselho de administração contará com a participação majoritária de representantes da sociedade civil que usam os serviços da organização; a experiência da adoção do orçamento participativo por parte de algumas administrações locais brasileiras, como Porto Alegre e Brasília; a experiência de atendimento ao cidadão - SAC, realizado pelo governo do estado da Bahia a partir da integração da prestação do serviço ao público envolvendo as diversas esferas de governo em locais de grande concentração populacional com elevado padrão de atendimento e avaliação permanente por parte dos usuários. Em Portugal, o INFOCID, experiência baseada na disponibilização de informações ao cidadão em quiosques, a partir de um sistema global e integrado, utilizando tecnologia multimídia. Na Grã-Bretanha, o programa de melhoria da qualidade na prestação dos serviços públicos (Citizen's Charter), onde são estabelecidos padrões de atendimento e mecanismos de avaliação sobre a performance dos serviços prestados à população. Nos EUA, a experiência realizada por algumas administrações locais, de distribuição de vales educacionais para a comunidade, transferindo para o cidadão a decisão sobre a escolha da escola mais adequada para matricular seus dependentes.

Assim, repensar o controle é uma responsabilidade coletiva. Envolve a sociedade a partir do desenvolvimento permanente do conceito de cidadania. Envolve, também, toda a administração pública que precisa se preparar para essa nova realidade. Nesse sentido torna-se fundamental construir uma nova visão do controle a partir da capacitação dos quadros técnicos e gerenciais, tanto no núcleo estratégico quanto nas instituições executoras das políticas públicas visando a adequação aos novos requerimentos. No caso brasileiro vale destacar os esforços pioneiros de antecipação que vêm sendo promovidos pela Secretaria Federal de Controle, órgão do Ministério da Fazenda, e pelo Tribunal de Contas da União no sentido de acompanhar as tendências e implementar programas de aperfeiçoamento contínuo de métodos e sistemática de atuação, além dos investimentos realizados no campo do desenvolvimento dos seus recursos humanos. 


\section{Construindo a aliança estratégica necessária: à guisa de conclusão}

Realizar um processo de transformação, que envolva mudança de cultura e atitudes não é tarefa trivial. Ao contrário, requer habilidade e liderança para a condução do processo, que certamente acontecerá num contexto caracterizado por resistências e ambigüidades. Toda mudança cria um clima de instabilidade, o que é natural, diante do novo, que supõe um custo inicial de aprendizado. Também, inevitavelmente associada a um processo de transformação, está a possibilidade de ganhos e perdas, na perspectiva dos atores envolvidos no processo.

No sentido de enfrentar os obstáculos naturais, nesse contexto de mudança, torna-se fundamental estabelecer uma estratégia que viabilize o processo, por intermédio de mecanismos que neutralizem as ameaças e potencializem as oportunidades. Peter Senge, em $A$ Quinta Disciplina, enfatiza que o sucesso de uma organização está diretamente relacionado à sua capacidade de aprender: "as melhores organizações do futuro serão aquelas que descobrirão como despertar o empenho e a capacidade de aprender das pessoas em todos os níveis da organização." Isso significa muito mais do que obter informação. Em palestra para o programa Leadership and Mastery, compilada por RAY e RINZLER (1993), Senge afirma: "aprender tem muito pouco a ver com informar-se. Em essência, aprender consiste em melhorar a capacidade. Aprender é criar e construir a possibilidade para fazermos aquilo que antes não podíamos. $\mathrm{O}$ aprendizado está intimamente relacionado com a ação, o que não acontece com a absorção de informação. Uma das razões pelas quais o aprendizado tradicional é tão aborrecido é esta: a absorção de informações é aborrecidíssima, passiva demais. Já o verdadeiro aprendizado está sempre no corpo, liga-se à ação."

Assim, é fundamental explicitar com bastante objetividade os resultados pretendidos com a mudança e as conseqüências positivas e negativas, visando a ampliar o espaço de adesão. Normalmente associa-se risco à mudança, mas, muitas vezes o risco maior está em não mudar!

Nos processos de transformação organizacional, tanto no âmbito da administração de empresas, quanto no da administração pública, dois são os elementos-chave, que funcionam como sujeito e objeto da mudança: quem presta o serviço e quem dele se beneficia . A mudança será sempre conduzida pelas pessoas que prestam o serviço para as pessoas que usam o serviço. No caso da administração pública, 
essa abordagem motiva a discussão da necessidade de construção de uma importante aliança estratégica entre servidores e cidadãos na direção de um objetivo comum, qual seja, o de (re)construir um Estado que permita ao cidadão o exercício pleno da cidadania, por intermédio de servidores do público. O que nos remete à origem deste artigo, já que a governabilidade necessária para garantir a legitimidade é dada pelo cidadão, que elege seus representantes, e a governança, que significa a construção das capacidades de governar, é dada pelos servidores, que prestam o serviço ao público.

\section{Referências Bibliográficas}

ABRUCIO, F., "O impacto do modelo gerencial na administração pública: um breve estudo sobre a experiência internacional recente", Projeto Resenhas Bibliográficas, ENAP, Brasília 1996.

Bresser Pereira, L.C., "Da Administração Pública Burocrática à Gerencial", Revista do Serviço Público, ENAP, volume 120, n.1 jan/abr-1996.

Crozier, M., Estado modesto, Estado moderno - FUNCEP Brasília, 1989.

Etızıoni, A., Organizações Modernas, Biblioteca Pioneira de Ciências Sociais, São Paulo 1967.

Gore, A., The National Performance Review tradução e adaptação de Helena Pinheiro, MARE 1996.

Guerreiro Ramos, A., Administração e Estratégia do Desenvolvimento, Rio de Janeiro: Fundação Getúlio Vargas 1966.

KLIKSBERG, B., "Nuevas fronteras tecnológicas en matéria de gerencia en América Latina", Revista de la Cepal abril 1987.

Martins, L., "Reforma da Administração Pública e Cultura Política no Brasil: Uma Visão Geral", Cadernos ENAP No 8, Brasília 1995.

Matus, C., Política, Planejamento e governo, Editora Ipea 1995.

Ministério da Administração Federal e Reforma do Estado, "Plano Diretor da Reforma do Aparelho do Estado" - Presidência da República, Câmara da Reforma do Estado, Brasília, novembro, 1995.

- "Nota técnica sobre missão de cooperação técnica do governo francês" — Elaborada por Ciro Penafort, MARE 1996.

Merton, R., Social Theory and Social Structure, Glencoe III The free prees 1957.

Osborne, D. \& Gaebler, T., Reinventando o governo- Como o espírito empreendedor está transformando o governo, Brasília: MH Comunicação, 1994.

Plowden W., "A Reforma Administrativa na Grã-Bretanha (1965-1982)" - Revista de Administração Pública jan/março 1984.

RAY, M. e RINZLER, A., O novo paradigma nos negócios - estratégias emergentes para a liderança e mudança organizacional, São Paulo: Cultrix - Amana 1993. 
Ramamurti, R., "Planejamento Estratégico em empresas dependentes de governo", Journal Range Planning vol 19 junho 1986.

Senge, P., A quinta disciplina - arte, teoria e prática da organização de aprendizagem, São Paulo: Editora Best Seller 1990.

Thompson, V., Moderna Organização, Rio de Janeiro: Programa de Publicações Didáticas USAID, 1967.

\section{Resumo}

Resumen

Abstract

Crise e reforma do Estado: uma questão de cidadania e valorização do servidor Caio Márcio Marini Ferreira

O artigo discute a evolução recente da problemática da crise do Estado a partir dos três movimentos voltados para a sua superação: a busca da eficiência, a melhoria da qualidade e o resgate da esfera pública como instrumento do exercício da cidadania. Em seguida são analisadas as limitações impostas pelo modelo burocrático de administração pública e apresentadas as experiências recentes de reforma nos EUA, Grã-Bretanha, França e Brasil. São também avaliados os impactos do novo modelo de gestão pública nas áreas de planejamento, controle e desenvolvimento de pessoal. Finalmente o artigo discute o contexto de mudança e transformação do Estado destacando a necessidade de vincular os conceitos de governabilidade e governança aos de cidadania e valorização do servidor público.

Crisis y reforma del Estado: Una cuestión de ciudadanía y valorización del funcionario público

Caio Márcio Marini Ferreira

El artículo debate la evolución reciente de la problemática de la crisis del Estado a partir de los tres movimientos dirigidos hacia su superación: la búsqueda de la eficiencia, la mejoría de la calidad y el rescate de la esfera pública como instrumento de ejercicio de la ciudadanía. A continuación, se analizan las limitaciones impuestas por el estándar burocrático de administración pública y se presentan los experimentos recientes de reforma en los EE.UU., Gran Bretaña, Francia y Brasil. También se evalúan los impactos del nuevo modelo de gestión pública en las áreas de planificación, control y desarrollo de personal. Finalmente, el artículo trata del contexto de cambio y transformación del Estado resaltando la necesidad de vincular a los conceptos de gobernabilidad y Gobierno a los de ciudadanía y valorización del funcionario público.

State crisis and reform: a question of citizenship and civil servant merit recognition. 